\title{
Ethical challenges of big data information technology
}

\author{
Weisheng Wen', Jun Ma², Shuqin Liu', Quansi Wen³, Zhihong $\mathrm{He}^{2}$, Zhiyong Ren ${ }^{2}$ \\ ${ }^{1}$ School of management, Guangzhou Huali Science and Technology Vocational College, \\ Guangzhou, China \\ ${ }^{2}$ Guangzhou Huali Science and Technology Vocational College, Guangzhou, China \\ ${ }^{3}$ School of Computer Scicence \& Engineering, South China University of Technology, \\ Guangzhou, China
}

Email: wsw8681@126.com (Weisheng Wen),wwsg1102@sina.com (Jun Ma), sosogogo20091214@163.com (Shuqin Liu),qwen2012@foxmail.com (Quansi Wen), he_zh5929@163.com (Zhihong He), randy202112@163.com (Zhiyong Ren)

\begin{abstract}
The key to the value of big data lies in its application. The big data industry is rapidly developing into a new generation of information technology and service formats, that is, collecting, storing and correlation analyzing a large number of data with scattered sources and diverse formats, and discovering new knowledge, creating new value and improving new capabilities. The new generation of information technology revolution represented by big data and artificial intelligence is widely and profoundly affecting and changing human society, promoting social development, and changing the way of human survival and social interaction. Big data is the new engine for the information industry to become a sustained and rapid economic and social growth. New industries, new products and new services emerging from the new technological revolution facing the big data market. Because of this, the impact of big data information technology on individuals and society has attracted people's attention. At
\end{abstract}


present, the discussion of big data information technology involves advocacy of positive impacts, as well as warnings about privacy violations, discrimination, loss of skills, negative economic impacts, moral responsibility, security risks of key infrastructure and long-term impact of social well-being. Only in line with human moral values and ethical principles, this product of the high-tech era can fully realize its benefits.

Keywords : big data, artificial intelligence, information ethics

\section{I. "ETHICS" OF BIG DATA INFORMATION TECHNOLOGY}

The ethics of economics is the endogenous variable of economic development. Big data is closely related to people, For example, in medical field, there are technologies for premature infants, which can read more than 3000 data per second. By analyzing these data, the hospital can know which premature infants have problems and take measures in advance to increase their survival rate. Due to the role of utility value, efficiency first doctrine occupies the dominant position in economy and society, that is, the efficiency of manufacturers and the utility of consumers dominate everything, and it becomes the highest standard. As an exogenous variable, social and cultural environment includes material production and consumption mode, social organization and management system, values and ethics, as well as human behavior norms, human cognition of things, organization of production mode, norms of human behavior, etc. The development of social and cultural environment is a major progress in the form of human civilization, concept, and civilized development mode. Good ethics is the guarantee for the progress of social and cultural environment.

In the designprocess of big data product, ethical decision-making point is particularly important, which will affect the depth of data use. Organizations and individuals seek the ethical decision-making point of interest balance through investigation and negotiation. As decision-making subjects, organizations and individuals often aim their own interests and it is difficult to make objective decisions. Third party institutions can be introduced to conduct objective research and jointly find the ethical decision-making point. With the revolution of big data and information technology, artificial intelligence creation is not only a technical tool. It can be seen that big data information technology is a strategic technology, which not only 
effectively promotes economic and social development, but also brings a series of risks and challenges. Among them, ethical risk is an important aspect.

Big data, supported by massive information and data, big data is developing rapidly and widely, and showing the characteristics of cross-border integration, man-machine cooperation, open group intelligence, autonomous control and so on. Acquire, store and analyze more information and data. Information related to personal privacy, such as personal identity, privacy disclosure and information disclosure, is often stored, copied and disseminated in the form of data. If there is no ethical code, it may induce the ethical and moral risk of privacy disclosure. In addition, with the improvement of artificial intelligence autonomy, the judgment of causality, fault and other elements in artificial intelligence tort liability is becoming more and more complex. The ownership of rights and responsibilities in the application of artificial intelligence has also been widely concerned and discussed. There are ethical and moral risks in the development of artificial intelligence. More and more artificial intelligence products have the similar ability with human thinking, and even surpass human thinking in some aspects, which not only promotes economic and social development, but also brings series of risks and challenges.As shown in figure 1, big data information technology has changed the relationship between people and artificial intelligence creations, and traditional ethics will be deconstructed to build the ethical relationship in the era of big data.

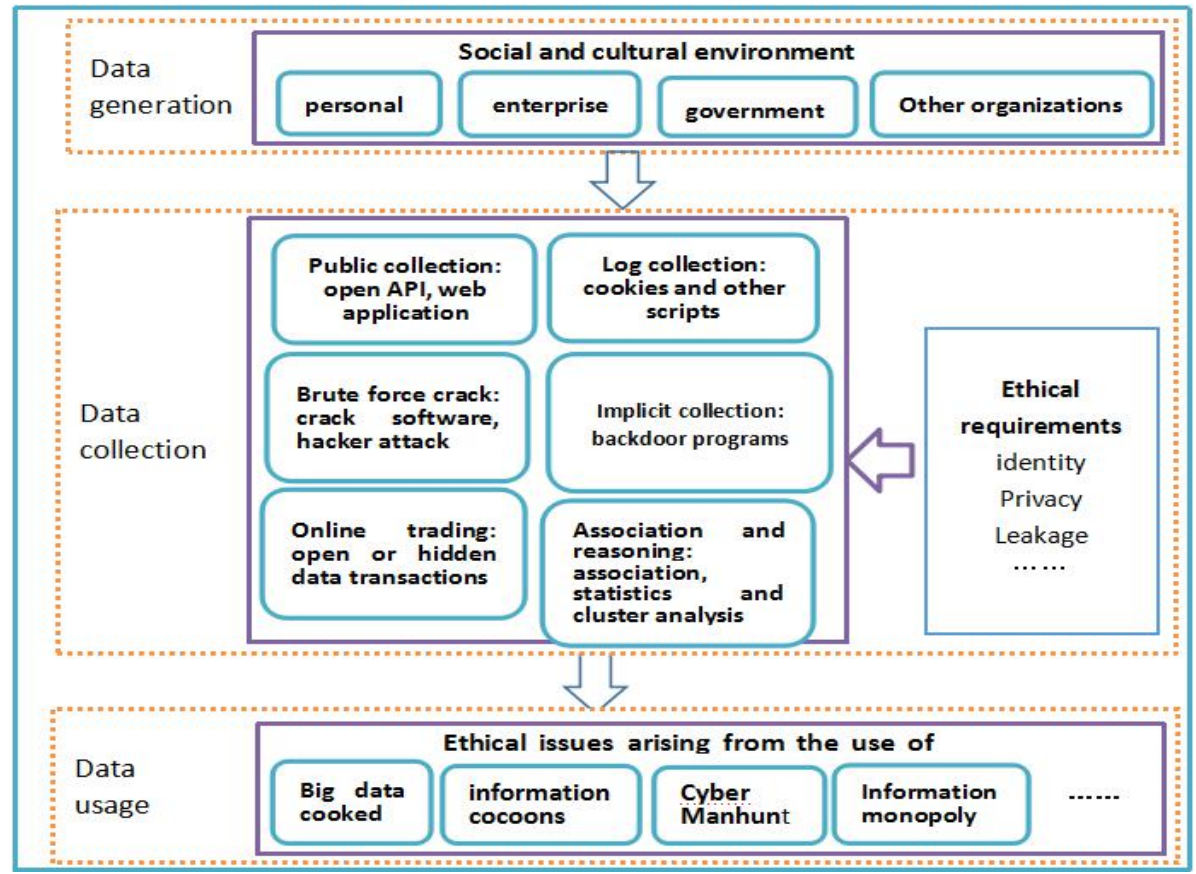

Figure 1: Ethical relationship in the era of big data 
As can be seen from Figure 1, the big data era is affected by different social and cultural environments. Ethics in different environments restrict the behavior of different social subjects. The rapid development of information technology gradually gets rid of the limitations of space and time and promotes the development of economy and society, which provides a new opportunity for the construction of integrity system based on ethics.

(1) Artificial intelligence is the most important technological and social change. A new generation of information technologies and products such as artificial intelligence, intelligent network vehicles, virtual reality and UAVs will be displayed together with consumption, life service industry, unmanned stores, intelligent care, intelligent transportation, vigorously develop new services such as intelligent logistics and intelligent home, and guide enterprises to carry out mass customization services for different groups and market segments by using emerging technologies such as big data information, Improve the social and cultural environment.

(2) The government actively promotes various government affairs, uses big data information to carry out convenient services and improve the social and cultural environment. Big data technology has been solving the problems of difficulties in work and work, slow work and complicated work. It has promoted important tasks such as approval services, the convenience of Internet plus government services, and the integration and sharing of government information systems, so as to enhance the social and cultural environment of big data technology.

(3) Other organizations use big data to help more people and improve the social and cultural environment. It is imperative to promote the construction of big data integrity system and build a unified data platform. Build an integrity data platform in the technical standards of data collection, coding, exchange and management, also the technical standards of credit products, credit services and credit management, so as to realize the sharing and mutual communication of integrity data.

(4) Individuals promote the construction of integrity system and improve the social and cultural environment through big data information technology. Individuals use search tools to obtain information, consume through purchase platforms, communicate instantly through social tools, and obtain more needed information through government and other organization websites. 
Our production and life are inseparable from big data. Big data has the characteristics of large data scale, diverse sources, complex structure, fast collection speed and high commercial value. Because these data have high commercial value, driven by the profit seeking nature of capital, enterprise data collection and application are prone to immoral behavior.

(1.) Public collection: Apps such as API and Web can be used to collect personal information such as age, preferences, personal income of consumers. After obtaining such data, they can be exploited and utilized without consent or even traded as resources, thus violating the privacy rights of consumers.

(2) Log collection: Web sites use cookies to record and count user visits, pages visits and time spent on each page. The use of these data violates consumers'rights.

(3) Violence collection: such as hacking corporate software systems to obtain important information from consumers or businesses.

(4) Implicit collection: Some software, such as Android-Ios backends, can monitor consumers'daily lives and thus violate their privacy.

(5) Buying and selling on the Internet: Violating the rights and interests of consumers by buying and selling consumer data through various unconventional means.

(6) Relevance, Inference: By analyzing the weak connections between scattered data, infer the direct connections between data, which leads to information disclosure.

Our production and life are inseparable from big data. Big data has the characteristics of large data scale, diverse sources, complex structure, fast collection speed and high commercial value. Because these data have high commercial value, under the nature of capital profit, the process of data collection and application needs to strengthen ethics..

\section{ECONOMIC AND ETHICAL BEHAVIOR OF BIG DATA INFORMATION}

Adam Smith (British economist 1723-1790) put forward and systematically demonstrated the concept of "economic man" and introduced moral analysis into economic theory, which further unified "economic man" and "moral man" and made morality the object of economic analysis. 
Since the industrial revolution, data has experienced outbreaks again and again to promote economic and social development.

From the perspective of economics, morality has the economic connotation of interest, cooperation, contract and fairness. Traditional social communication is mainly limited to acquaintances. The reason why people abide by ethics is largely because there is no external supervision in the relatively small circle of acquaintances. Moreover, some people's adherence to ethics is mainly limited to the relatively small circle of acquaintances, and they may not keep faith with people outside the circle. Modern social communication increasingly breaks through the scope of traditional acquaintance communication, and builds the Internet based on powerful information technology to further break the space-time limit of traditional communication and make it a universal social communication. This requires people to have a higher degree of moral self-discipline, a higher degree of tolerance and respect, so as to promote the formation of modern social morality based on universal honesty and trustworthiness.

The Internet is a real-time, dynamic and open social platform. In the process of big data product design and service, personal value with organizational value are combined, to personal value with organizational value are combined, to improve the value consistency between the organization and its members, and the value consistency between managers, engineers and users in the organization, also take into account the acceptability of users in product design, produce products in line with common values and avoid unethical behavior, At the same time, more people will be educated unconsciously while allowing immoral actors to bear pressure. We should play a broader and more effective role in public opinion supervision, condemnation and enlightenment. Figure 2 shows the relationship between "economic environment" and "moral behavior" in the era of big data. 


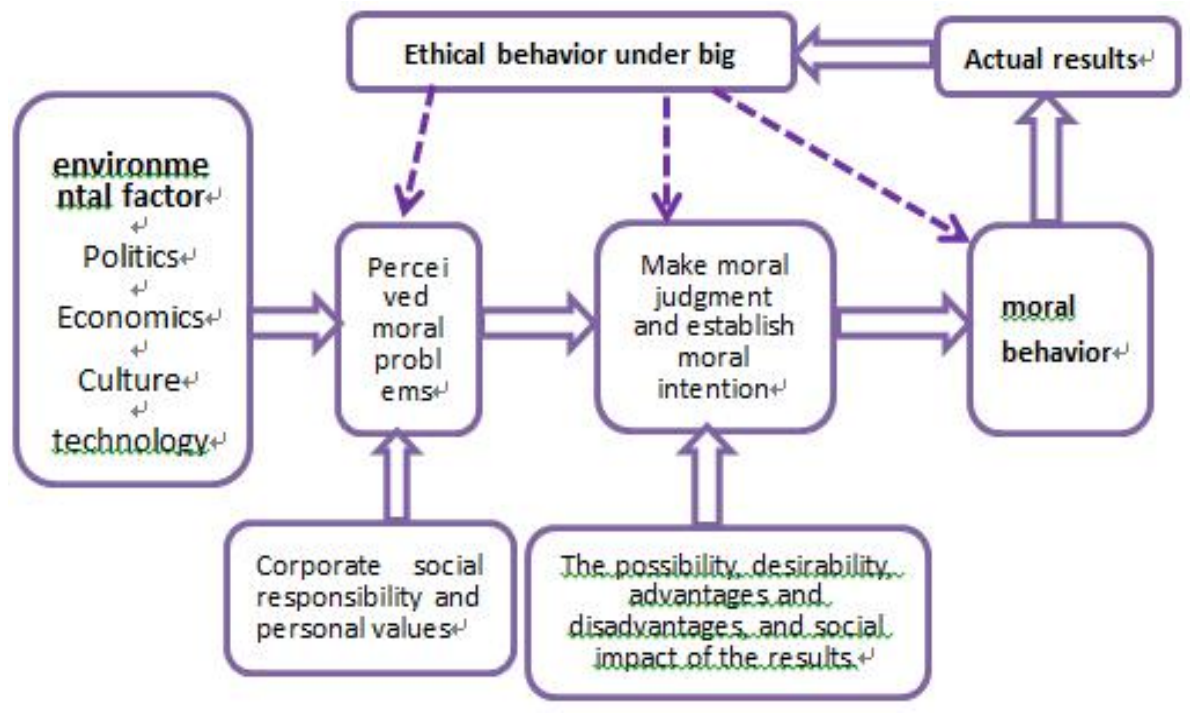

Figure 2: relationship between economic and ethical behavior in the era of big data

As shown in Figure 2, the moral behavior of an individual or an enterprise under big data is not fixed. It perceives ethical constraints and makes decisions based on the specific scenario, and then adjusts its behavior based on the consequences of the outcome.The perception of individual or enterprise's moral behavior is not only influenced by macro-environmental factors such as politics, economy, culture and technology, but also by the values they hold.Decisions constrained by moral perception are influenced by the comparison of benefits and losses, the possibility of outcomes, and society. The results of the implementation of the decision in turn affect consumers're-evaluation of the decision, consumers will learn from experience, and adjust moral perception and decision-making.In this process of constant amendment, ethical constraints on individuals and society are becoming more and more standardized.

In the era of big data, information access and use should be based on standardized ethics and protect personal privacy. However, the purpose and scope of data use are not clear at the beginning of collection, and it is impossible to inform in advance. Once information is used by people with ulterior motives for private interests, it will bring permanent disaster. In the application of big data technology, a large number of moral problems have arisen::

(1) Big data killing: in recent years, for the same goods or services, the price is more expensive for old customers, when comparing with new customers.

(2) Information cocoon room: People's information field will be habitually guided by their own interests, so as to shackle their life to a "cocoon room" like a cocoon. Because 
information technology provides a more self thinking space and a large amount of knowledge in any field, some people may further escape various contradictions in society and become isolated from the world. While the communication within the community is more efficient, the communication between communities is not necessarily smoother and more effective than in the era of lack of information.

(3) Human flesh search: use big data information to search the relational network community activities of looking for people, asking people, touching people, getting close to people and crowding people, and change the single query process into a humanized search with one person asking questions and multiple answers. Human flesh search is a super powerful search means through the combination of network and manual search, by fully mobilizing the strength of Internet users, concentrating the attention of Internet users, searching for the information and data of a person or thing on the network, determining the real identity of the searched object, and exposing it to the Internet world.

(4) Data monopoly: from data to information, it needs to go through the process of data collection, processing, storage and analysis. Improving data concentration can improve data production efficiency. When human society gradually enters informatization and digitization, data is easy to be used by data oligarchs because of its scale and diversity, so as to monopolize specific industries. Data monopoly monopolizes the market, consumers and products through the collection, mining and use of data, so as to form a market barrier.

In the era of big data, the decision-making point of information ethics is particularly important. Decision makers, organizations and individuals often start from their own interests and it is difficult to make decisions objectively. The ethical and moral risks brought by big data information can be predicted. The asymmetry and opacity of information and the inevitable knowledge and technical threshold of information technology will objectively lead to and exacerbate phenomena and trends that violate the principle of social equity, such as information barriers and digital divide. How to narrow the digital divide to improve the overall welfare of mankind and ensure social equity is a worldwide ethical value problem. While accelerating the dissemination, collection and sharing of big data, information technology also provides loopholes and black networks for some countries or organizations to use network hegemony to interfere in other countries' internal affairs or carry out network attacks, which seriously threatens national sovereignty and security. Therefore, preventing data hegemony is an important content of safeguarding national sovereignty in the information age. Some 
phenomena and trends in the Internet era should be highly valued. For example, some people are addicted to the virtual world on the Internet and don't like interpersonal communication in the real world. This immoral way of life fundamentally negates the significance and value of traditional social ethical life, abandons its own ethical subject status and corresponding ethical responsibility, which touches a more fundamental level of values foundation.

\section{THE DEVELOPMENT OF BIG DATA INFORMATION AND THE GUARANTEE OF ETHICS}

With the rapid development of information technology in the era of big data, to effectively deal with the ethical challenges brought by information technology, we need to conduct in-depth research and establish correct morality, values and the rule of law. Build a protection mechanism for ethical and moral risks brought by information development in the era of big data..

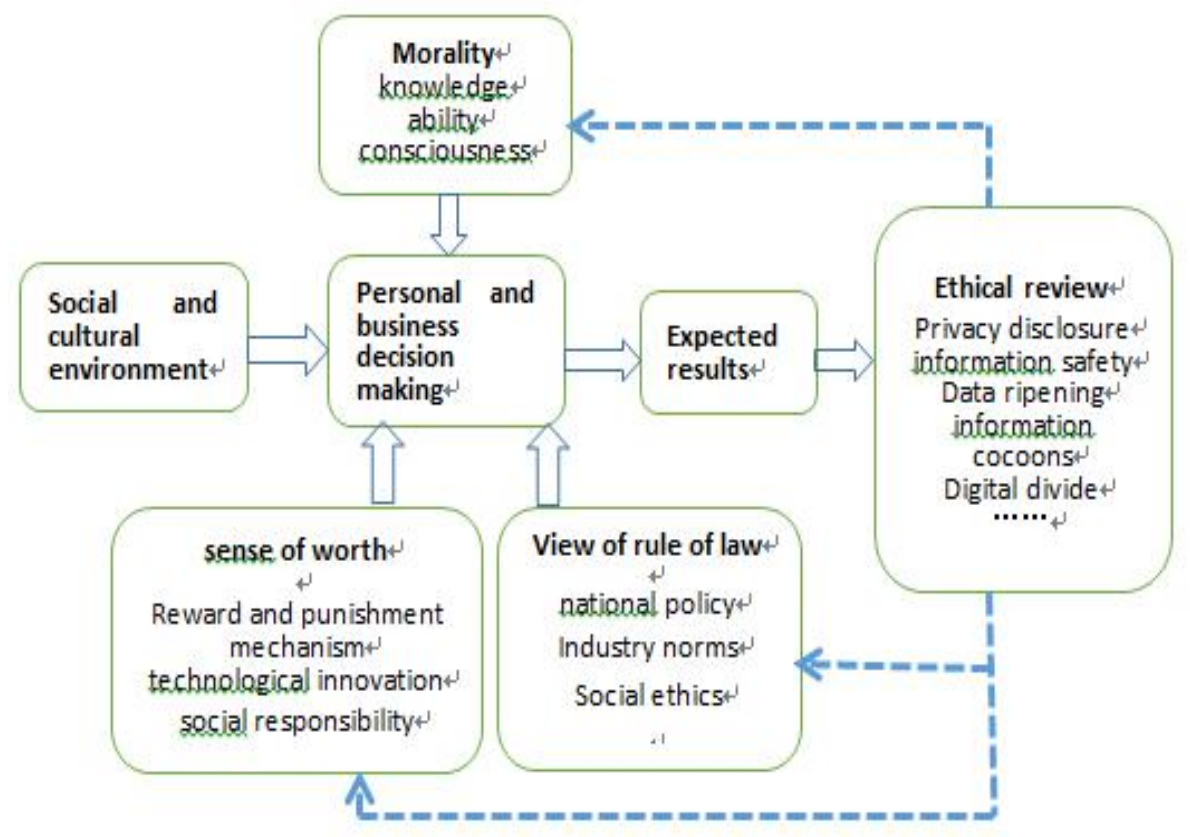

Figure 3: ethics and moral hazard protection mechanism of big data

As shown in Figure 3, The application of information technology should adhere to the correct moral concept to meet the needs of the people. Information technology must bring well-being, convenience and enjoyment to the broad masses of the people, instead of being exclusively enjoyed by a few people, and stick to the advocacy of "Do more good and less bad". We should take the new generation of information technology as an important means to meet people's basic needs, safeguard people's fundamental interests, and promote people's long-term 
development. At the same time, ensure public participation and wield individual rights, encourage the public to propose questions or valuable feedback, so as to jointly promote the improvement of the performance and quality of information technology products. It is necessary to ensure that human beings are always in the dominant position, and man-made objects are always placed in the controllable range of human beings, to ensure that human interests, dignity and value subject status are not damaged, and that any information technology, especially artificial intelligence machines with autonomous consciousness, hold the same basic values as human beings. Always adhere to the moral bottom line of not harming people themselves, and pursue the correct value orientation of benefiting mankind.

The values of the information technology application should be safe, reliable and controllable. In the era of big data, two things cannot be avoided. First, the data generated by users will be stored in the cloud and on the servers of various manufacturers. Second, the ability of data acquisition is more powerful and the range of data acquisition is wider. Now there is not only the mobile Internet, but also the Internet of things and the Internet of vehicles in the future. There will be more intelligent devices. After the popularity of these hardware, you will find that the scale of data generated by users using these devices will be unprecedented. The information system should be protected from danger, threat and accident. From the technical point of view, the goal of information security and confidentiality is mainly reflected in the confidentiality, integrity, authenticity, reliability, availability, non repudiation of the system.It is necessary to ensure the information security of the nation, enterprises and various organizations, the privacy security of users and the related political, economic and cultural security. If a certain science and technology may endanger people's status as the main value, no matter how functional it is, it should be stopped decisively.

The application of information technology is based on the rule of law, and should be adhered to the bottom line of ethics and morality. At present, the development of artificial intelligence has exposed many problems of technology and data anomie. Therefore, it is necessary to improve the risk accountability mechanism of intelligent technology and educational data, and realize the standardized supervision of intelligent technology and data. It is also necessary to strengthen the study, judgment and prevention of potential risks in the development of artificial intelligence, in order to safeguard people's interests and national security, and to ensure that artificial intelligence is safe, reliable and controllable. In the application of big data information, we should strengthen privacy protection, comprehensively use technological innovation, ethical norms, legal systems and other means to ensure the healthy development of 
big data information on the premise of meeting ethical norms. On June 17, 2019, China's new generation of artificial intelligence governance professional committee issued the "new generation of artificial intelligence governance principles - the development of responsible artificial intelligence", which requires that the development of artificial intelligence should respect and protect personal privacy, and fully protect individual's right to know and choose. At the legal level, we should speed up the formulation of laws and regulations to strengthen privacy protection, fully protect citizens' right to know and choose in the application of artificial intelligence, strictly regulate the collection, storage, processing and use of personal information in the application of artificial intelligence, and oppose theft, tampering, leakage and other illegal collection and utilization of personal information.

\section{CONCLUSION}

At present, we are in a new era of high-tech development. We should not only effectively prevent ethical and moral risks, but also speed up the development of big data information technology. In fact, the relationship between the application of big data information technology and personal privacy protection is not one or the other. We can guide the application of big data artificial intelligence information technology correctly from the ethical level through a variety of means to minimize the risk of privacy leakage. As an emerging technology, the application of science and technology promotes the development of economy and society. As a science and technology, big data information technology has no distinction between good and evil, right and wrong. The key lies in whether users can properly apply it on the premise of conforming to ethical norms.

\section{REFERENCES}

[1] FRIZZO-BARKER J,CHOW-WHITE P,HA V $\mathrm{T}$ D.Genomic Big Data and Privacy:Challenges and Opportunities for Precision Medicine[J].CSCW,2016,25:115-136.

[2] YU Xue,DUAN Weiwen.Ethical construction of artificial intelligence[J].Theoretical Exploration,2019(6):43-49.

[3] WANG Yu,CHENG Haidong.An analysis of the internal pathway of the ethics governance of artificial intelligence techniques[J].Journal of Dialectics of Nature,2019(8):87-93. 
[4] DUAN Weiwen.The basic approaches and meaning in the ethical construction of robot[J].Science and Society,2015,5(2):35-45.

[5] SU Lingyin.Can ethical principles be embedded in AI machines? - take driverless car as example[J].Theoretical Exploration,2018(3):38-45.

[6] ZHOU Tao.Ethical challenge brought by big data and artificial intelligence(Part 1) [J].Journal of UESTC(Social Sciences Edition),2018(5):01-06.

[7] XU Shenglong."Public" and "existing in public space" _ An ethical approach to big data[J].Philosophical Trends,2019(8):86-94.

[8] JIA Kai.Artificial intelligence and algorithm governance research[J].Chinese Public Administration,2019(1):17-22.

[9] LIU Pei,CHI Zhongjun.Ethical reflections on algorithmic discrimination[J].Journal of Dialectics of Nature,2019(10):16-20.

[10] Lu yaohuai and Luo Yating, 2017, privacy issues and ethical dimensions of personal information collection and processing in the era of big data, philosophical trends, No. 2, pp. 63-68

[11] Wang Tiansi: causality and its philosophical connotation in big data, China Social Sciences, No. 5, 2016. pp. 22-42

[12] Lu yaohuai and Luo Yating, 2017, privacy issues and ethical dimensions of personal information collection and processing in the era of big data, philosophical trends, No. 2, pp. 63-68.

[13] PAN Enrong,YANG Jiafan.A framework of technology-oriented ethics for artificial intelligence:On self-driving systems[J].Journal of Dialectics of Nature,2020(3):33-39.

[14] CHENG Shiwei.On ethical governance of transparent society in big data era[J].Studies in Dialectics of Nature,2019(6):68-72.

[15] DONG Jun,CHENG Hao.Risks and control of big data technology:Analysis based on the research on the ethical issues of big data in China[J].Studies in Dialectics of Nature,2017(11):80-85.

[16] TAN Jiusheng,YANG Jianwu.The ethical risk of artificial intelligence and its cooperative governance[J].Chinese Public Administration,2019(10):44-50.

[17] GAO Qiqi.Global good intelligence and collective intelligence:The normative goal of artificial intelligence in global governance[J].World Economics and Politics,2019(7):2448. 
[18] MEI Liang,WU Xintong,WANG Weinan.Responsible governance of scientific and technological innovation:from open science to open society[J].Science Research Management,2019(12):01-10.

[19] WANG Liang.Discussion on "unidirectional emotional" ethical risk arising from social robots[J].Studies in Dialectics of Nature,2020(1):56-61. 